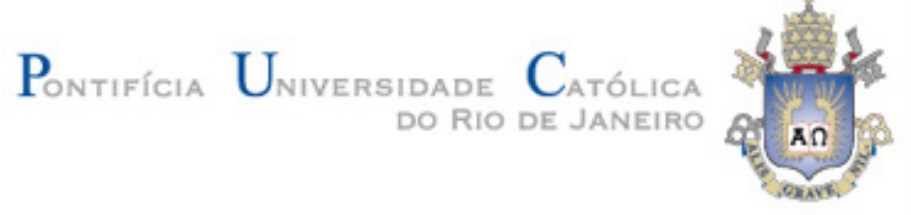

Flavia Garcia Serpa

\title{
Modelo de programação matemática para suporte à decisão na compra e distribuição de dutos e umbilicais
} decisão na compra e distribuição de dutos e umbilicais

\begin{abstract}
Dissertação de Mestrado
Dissertação apresentada como requisito parcial para obtenção do grau de Mestre (opção profissional) pelo Programa de Pósgraduação em Engenharia de Produção do Departamento de Engenharia Industrial da PUC-Rio
\end{abstract}

Orientador: Prof. Silvio Hamacher

Rio de Janeiro

Março de 2012 


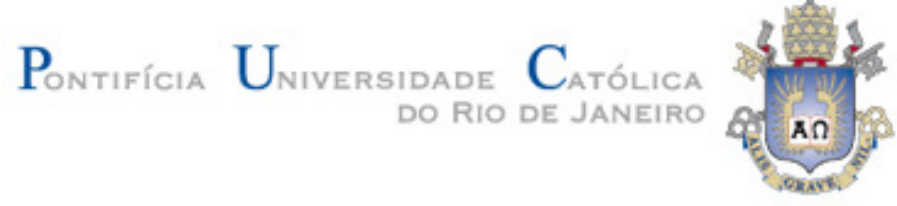

Flavia Garcia Serpa

\title{
Modelo de programação matemática para suporte à decisão na compra e distribuição de dutos e umbilicais
}

\begin{abstract}
Dissertação apresentada como requisito parcial para obtenção do grau de Mestre (opção profissional) pelo Programa de Pósgraduação em Engenharia de Produção do Departamento de Engenharia Industrial da PUC-Rio
\end{abstract}

Prof. Dr. Silvio Hamacher

Presidente e Orientador

Departamento de Engenharia Industrial - PUC-RJ

Dr. Carlos Fernando Fontenelle Dumans

PETROBRAS

Prof. Dr. Luiz Felipe Roriz Rodriguez Scavarda do Carmo Departamento de Engenharia Industrial - PUC-RJ

Prof. Dr. José Eugênio Leal

Coordenador Setorial do Centro Técnico Científico - PUC-RJ

Rio de Janeiro, 28 de Março de 2012 
Todos os direitos reservados. É proibida a reprodução total ou parcial do trabalho sem autorização da universidade, da autora e do orientador.

\section{Flavia Garcia Serpa}

Graduou-se em Química Industrial na PUC-RJ em 1984. Cursou Gestão Empresarial na FGV-RJ e Gestão Empresarial Avançada na COPPEAD. Trabalha na PETROBRAS desde 1985 como analista de sistemas, tendo atuado no desenvolvimento de sistemas na área de logística de transporte de E\&P, no planejamento da logística de transporte de E\&P. No momento, atua em planejamento e gestão da Unidade de Serviços de Contratação do E\&P Serviços.

Ficha Catalográfica

Serpa, Flavia Garcia

Modelo de programação matemática para suporte à decisão na compra e distribuição de dutos e umbilicais / Flavia Garcia Serpa; orientador: Silvio Hamacher - 2012.

73 f.: Il. (color.) : $30 \mathrm{~cm}$

Dissertação (Mestrado) - Pontifícia Universidade Católica do Rio de Janeiro, Departamento de Engenharia Industrial, Rio de Janeiro, 2012.

Inclui bibliografias

1. Engenharia industrial - Teses. 2. Logística. 3. Modelo matemático. 4. Planejamento. 5. Apoio à decisão. I. Hamacher, Silvio. II. Pontifícia Universidade Católica do Rio de Janeiro. Departamento de Engenharia Industrial. III. Título

CDD: 658.5 
À minha família, meus pais Ivan ${ }^{\dagger}$ e Solange pela minha formação e educação, meu marido José Eduardo pelos nossos 25 anos de conquista e meus filhos, Isabel e Artur, meus presentes de Deus. 


\section{Agradecimentos}

Ao José Eduardo, Isabel e Artur pelo incentivo, carinho e, sobretudo paciência durante este período do mestrado.

Ao Prof. Silvio Hamacher pela assertividade nas suas orientações, sempre contribuindo para o desenvolvimento deste trabalho e por estender a mão em um momento difícil.

Ao Sr. Eberaldo de Almeida Neto pela confiança durante todo o tempo que trabalhamos juntos.

Aos Drs. Carlos Fernando Fontenelle Dumans e Luiz Felipe Roriz Rodrigues Scavarda do Carmo por aceitarem o convite para compor a banca examinadora.

Ao Sr. Marcos Antônio Rodrigues Marques pelas orientações e informações sobre engenharia submarina. Sem sua ajuda, esta dissertação não seria possível.

À Sra. Evely Forjaz Loureiro e ao Sr. Carlos André Campos Ayres por me convencerem a não pedir demissão em 1998.

Ao Sr. Último Melo Mariz pela “dica” sobre o tema da dissertação.

Ao Sr. Vinícius Chagas de Oliveira pela disponibilização de dados do SAP ao longo do trabalho.

Ao Dr. Leonardo Souza Ribeiro e ao Sr. João Batista de Andrade Neto pela ajuda nas últimas revisões.

À equipe que trabalha comigo pelo constante apoio. 


\section{Resumo}

Serpa, Flavia Garcia; Hamacher, Silvio (Orientador). Modelo de programação matemática para suporte à decisão na compra e distribuição de dutos e umbilicais. Rio de Janeiro, 2012. 73p. Dissertação de Mestrado (opção profissional) - Departamento de Engenharia Industrial, Pontifícia Universidade Católica do Rio de Janeiro.

A atividade de exploração e produção (E\&P) de petróleo no segmento offshore no Brasil apresentou um crescimento vertiginoso nos últimos anos e, com a descoberta do pólo pré-sal da bacia de Santos pela PETROBRAS, a expectativa é de que haja um incremento ainda maior. Dentro da cadeia produtiva de E\&P, uma etapa fundamental para garantir a produção de petróleo é a interligação dos equipamentos submarinos às Unidades Estacionárias de Produção. Esta interligação é feita através de dutos (rígidos ou flexíveis) e umbilicais, cujo mercado fornecedor é bastante restrito. Para que estes dutos e umbilicais sejam transportados até a locação, é necessário utilização de bases, que atuam como centro de distribuição na cadeia logística. Este trabalho apresenta um modelo de Programação Linear Inteira Mista cujo objetivo é de apoiar a decisão na compra e distribuição de dutos flexíveis e umbilicais, indicando, para cada demanda dos projetos, qual fábrica e qual base deverá ser utilizada. O modelo também permite uma análise sobre a influência do aumento na capacidade de produção no Brasil em relação aos custos logísticos e fabricação nacional. Como resultado desta análise, por exemplo, poderá ser observado que, em não havendo aumento da capacidade de produção no Brasil, além do que já foi previsto, as compras no mercado nacional, no período 2013 a 2016, representarão em torno de 70\% da demanda.

\section{Palavras-chaves}

Logística; modelo matemático; planejamento; apoio à decisão 


\section{Abstract}

Serpa, Flavia Garcia; Hamacher, Silvio (Advisor). Mathematical model to support decision making in the purchase and distribution of flowlines and umbilicals. Rio de Janeiro, 2012. 73p. Dissertação de Mestrado (opção profissional) - Departamento de Engenharia Industrial, Pontifícia Universidade Católica do Rio de Janeiro.

Offshore oil exploration and production activities in Brazil have presented an enormous rise in recent years and, following Petrobras's discovery of pre-salt accumulations in Campos Basin, an even greater rise is expected. Inside E\&P production chain, a fundamental step to achieve oil production is the connection of the underwater equipment to the stationary production units. This connection is made through the use of flowlines (both flexible and rigid) and umbilicals, which have a strict vendor market. In order to transport these flowlines and umbilicals to the well location, the use of an onshore base is required, acting like a distribution center in the logistics chain. This paper presents a model for Mixed Integral Linear Programming which aims to support the decision making process in the purchase and distribution of flowlines and umbilicals, indicating, for each project's demand, which factory and which onshore base shall be used. The model also allows an analysis of the influence of the increase in the production capacity related to logistics cost and national manufacturing. As a result, for example, the national market should account for $70 \%$ of the demand, between the years 2013 and 2016.

\section{Keywords}

Logistics; mathematical model; planning; decision making support. 


\section{Sumário}

1 Introdução 12

1.1. Objetivo 14

1.2. Metodologia 15

1.3. Estrutura do trabalho 15

2 Projeto submarino 16

2.1. O petróleo 16

2.1.1. Exploração 17

2.1.2. Perfuração 18

2.1.3. Produção 18

2.2. Sistema submarino 19

2.2.1. Classificação dos dutos e umbilicais 19

2.3. Construção do arranjo submarino 22

2.3.1. Instalação de dutos e umbilicais 23

3 Estudo de caso 24

3.1. Caracterização da empresa 24

3.2. Caracterização da operação 25

3.2.1. Compras de dutos e umbilicais 26

3.2.2. Bases de carregamentos 29

3.2.3. Contratações de embarcações PLSV 30

3.3. Descrição do problema 31

3.4. Análise da demanda de dutos 34

3.4.1.1. Previsão da Demanda e Correlação Linear 34

3.4.2. Análise dos dados 36

4 Modelos de programação linear 39

4.1. Premissas 39

4.2. Função objetivo $\quad 40$

4.2.1. Modelo determinístico 41

4.3. Modelo estocástico 47

4.4. Implementação 52 
5 Resultados

5.1. Demanda 2010 - 2011

5.2. Modelo determinístico - Demanda 2013 - 2016

5.3. Modelo determinístico - Demanda 2013 - 2016 com variações 62

5.4. Modelo estocástico - Demanda 2012 - 2016

5.4.1. Comparação entre modelos 64

5.4.2. Análise de capacidade das bases 67

6 Conclusões 68

6.1. Recomendações para futuros trabalhos 70

$\begin{array}{ll}7 \text { Referências Bibliográficas } & 71\end{array}$ 


\section{Lista de Figuras}

Figura 1 - Configuração de instalação de risers 20

Figura 2 - Estrutura interna do duto flexível 21

Figura 3 - Umbilical eletro-hidráulico 21

Figura 4 - Desenho esquemático de um arranjo submarino 22

Figura 5 - Embarcação PLSV 23

Figura 6 - Crescimento da produção de óleo e gás no Brasil 25

Figura 7 - Matriz de categorização de itens - Bens 27

Figura 8 - Localização das fábricas de dutos e umbilicais 28

Figura 9 - Histórico do estoque de dutos e umbilicais - Base Vitória-ES 30

Figura 10 - Fluxo dos dutos e umbilicais 32

Figura 11 - Localização das bases de carregamento 32

Figura 12 - Distribuição de custos 33

Figura 13 - Medidas de erros em previsão 36

Figura 14 - Correlação entre demanda de dutos e produção de petróleo $\quad 37$

Figura 15 - Projeção da demanda de dutos 38

Figura 16 - Sequência de etapas na otimização 52

Figura 17 - Custos logísticos - demanda 2010-2011 55

Figura 18 - Aquisição de dutos no exterior $\quad 55$

Figura 19 - Custo e capacidade de produção 56

Figura 20 - Custos logísticos para 1 base de carregamento $\quad 57$

Figura 21 - Custos logísticos para 2 bases de carregamento 57

Figura 22 - Custo logístico - demanda 2013-2016 58

Figura 23 - Parcelas do custo logístico - demanda 2013-2016 59

Figura 24 - Capacidade de produção no Brasil e custo logístico 60

Figura 25 - Capacidade de produção e compra de dutos no Brasil 61

Figura 26 - Estoque nas bases 62

Figura 27 - Estoque na base Vitória-ES $\quad 64$

Figura 28 - Estoque resultante do modelo estocástico 65

Figura 29 - Estoque nas bases - modelo estocástico 66

$\begin{array}{ll}\text { Figura } 30 \text { - Estoque x capacidade das bases } & 67\end{array}$ 


\section{Lista de Tabelas}

Tabela 1 - Classificação de itens adquiridos 26

Tabela 2 - Características das bases de carregamento $\quad 29$

Tabela 3 - Quantidade instalada de dutos e umbilicais 34

Tabela 4 - Cálculo do erro para a projeção de dutos 37

Tabela 5 - Aquisição de dutos por região $\quad 59$

Tabela 6 - Aquisição de dutos e umbilicais por região, considerando aumento $\begin{array}{ll}\text { de produção de dutos no Brasil } & 60\end{array}$

Tabela 7 - Utilização das bases $\quad 61$

Tabela 8 - Comparação entre cenários de demanda 2013-2016 63 